\title{
LA MUERTE INCOMPRENSIBLE DE PATROCLO (I 684 IN FINEM)
}

\author{
Silvia Ester Saravi \\ Universidad Nacional de la Plata, República Argentina
}

En relación con la temática central de la muerte heroica "en la guerra que da gloria a los hombres", hemos considerado, en un estudio anterior, la de Sarpedón, hijo de Zeus, como primer eslab'on paradigmático de una cadena de luchas y muertes principales cuyo orden el mismo Zeus revela en 0, 65-68 1 :

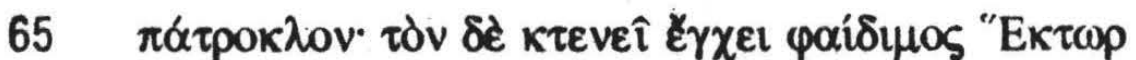

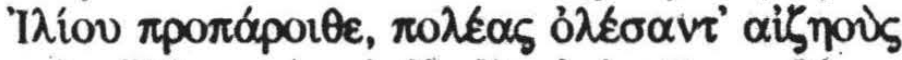

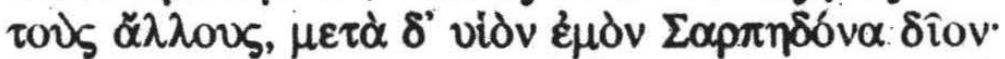

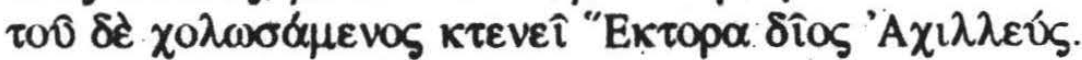

Sarpedón manifiesta su preclara concepción de la conducta heroica en $\mathrm{M}$, 310-328 2:

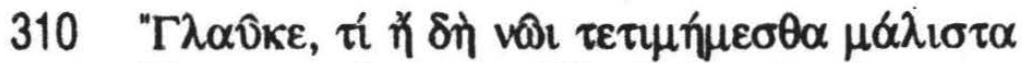

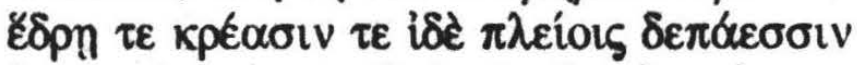

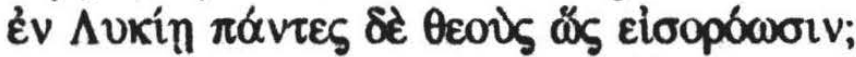

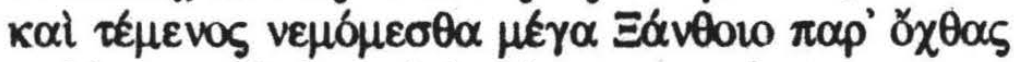

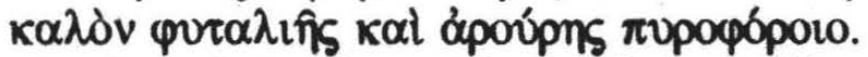

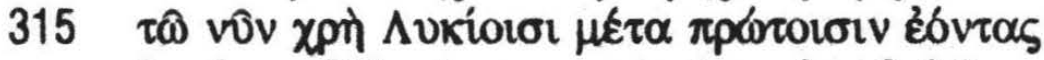

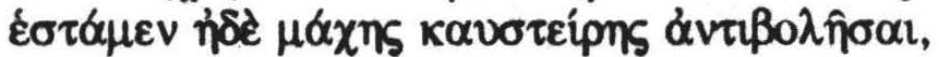
¿

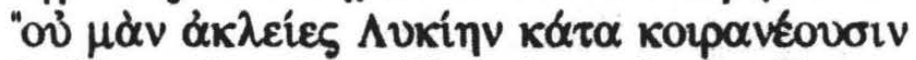

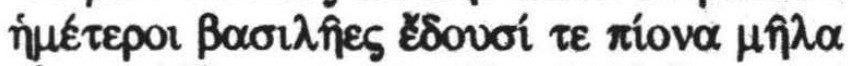

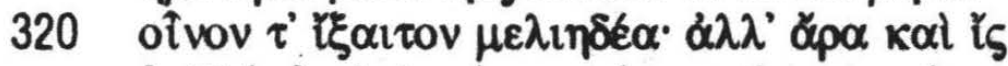

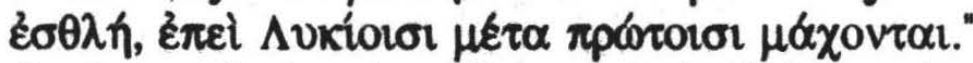

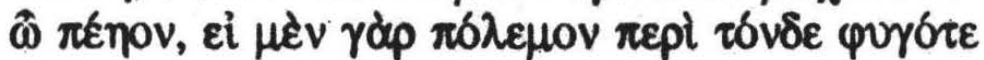

1. 0,65-68: "Patrocio morirá herido por la lanza del ilustre Héctor, carca de liión, después de quitar la vida a muchos jóvenes y, entre ellos, al divino Sarpedón, mi hijo. Irritado por la muerte de Patroclo, el divino Aquiles matará a Héctor."

2. $M, 310-328:$ " Glauco! ¿Por que a nosotros nos honran en Licla con asientos preferentes, manjares y copas de vino, $y$ todos nos miran como a dioses? También posoemos campos grandes y magnificos a arillas del Janto, con vilias y tierras fertiles. Por esto, es necesario que ahora nos mantegamos entre los que están en primera fila y enfrentemos la ardiente batalla, para que cualquiera de los licios, armados de fuertes corazas, diga: "No sin gloria, por cierto, imperan nuestros reyes en Licia y comen pingües ovejas y beben exquisitos vinos dulces como la miel, sino tambien su fibra es noble, puesto que luchan entre los licios que combaten en la primera fila." iOh querido! ¡Ojalá que, huyendo de esta batalla, nos libráamos de la vejez y de la muerte! Entonces, ni yo pelearia en la primera fila ni te impulsarla a ti hacia la batalla que da gloria a los valientes. Pero ahora, ya que son muchas las muertes apostadas para los mortales sin que éstos puedan rehuirlas o evitarlas, jvamos! y daremos gloria a alguien, 0 alguien nos la dará a nosotros." 


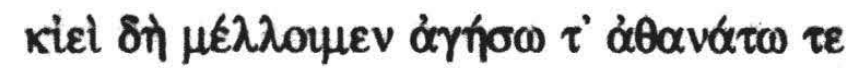

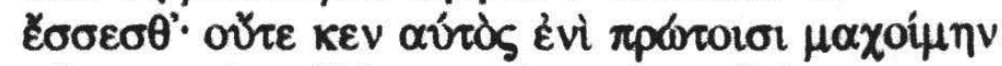

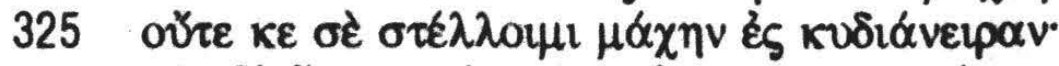

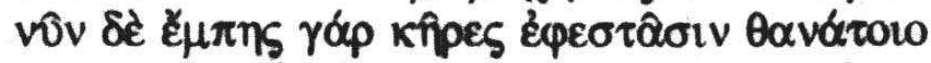

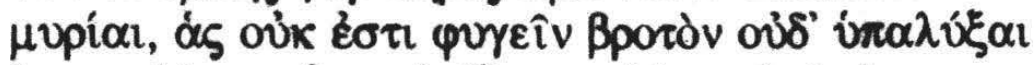

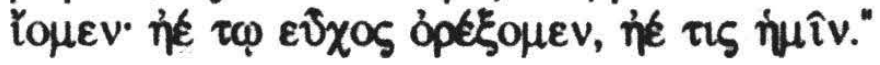

Expresa aquil las obligaciones ineludibles de un rey-guerrero, reunidas en su calidad de écolios (321) ${ }^{3}$, en dos momentos: 1) (322-325), reconocimiento y aceptación de la muerte, en contraste con la ausencia de vejez e inmortalidad de los dioses, y 2) (326-328), ponderación de la gloria ( $\varepsilon \hat{x} \chi 05)$ de la muerte en batalla como anhelo de perduración en el renombre. Desde esta perspectiva, el hijo de Zeus llega a ser el paradigma de Aquiles y el "decus" de todos los héroes. El hombre es mortal y obra en consecuencia. Esta nota resonará nuevamente al final de la llíada cerrando el itinerario espiritual de Aquiles, cuando comprenda, frente al cadáver de su enemigo, que a ambos los une la heroicidad de la mu erte $(\Omega, 518 \mathrm{ss})$.

Para Sarpedón 4 , la muerte, no tiene sorpresa ni temblor cuando le llega. De aquí que el heroísmo homérico es un asunto de intelección, no se define meramente por la acción, es una actitud que surge del reconocimiento de los límites mortales. Frente al circuito cabal de Sarpedón, los itinerarios de Héctor y Aquiles son procesos dinámicos entre aciertos y desaciertos que culminan en el descubrimiento y aceptación de la estructura dolorosa de la experiencia humana. La "sabiduría" de la llíada está expresada por Aquiles al cabo de su trayectoria, cuya síntesis es el famoso verso de $\Omega, 49$; en boca de Apolo:

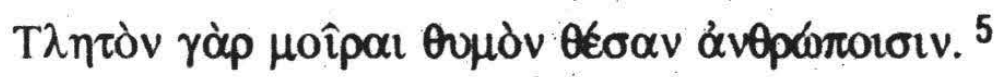

"Pues, las distribuidoras del destino pusieron a los hombres un corazón capaz de soportar".

La muerte de Patroclo, deslumbrante y terrible, contrasta, en el mismo Canto $\Pi$, con la majestuosa calda de Sarpedón. La crítica que centra su discusión en los versos 686 y siguientes:

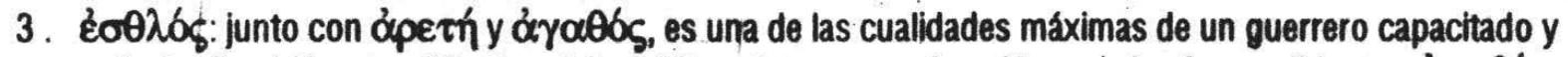
valiente. También es calificativo del espiritu y tiene una coloración moral más sensible que ór $\gamma \alpha 06$ s. Crr. Chantraine, 1968, p. 378.

4. Para el lector neoclásico (XVIII), Sarpedón ilustraba el ideal heroico, y era considerado asI desde el Renacimiento.

5. Hoîpod: sólo en este lugar, en la lliada, aparece en plural. Para Homero, no es persona ni tampoco deidad equiparable a los olimpicos, aunque presente su acción como un ser personal y operante. Es el marco o limite del poder de los dioses, ley natural que involucra al hombre desde que nace. El designio de la $\mu$ oîp $\alpha$ homérica es preponderantemente negativo, determina la calda, la decadencia. En ninguna parte del poema se habla de relación fatalista: nada de lo que acontece está ya dado de antemano. En este pasaje, el plural, las relaciona con las hesiódicas que son tres, e hijas de Zeus y Temis (Toogonla,

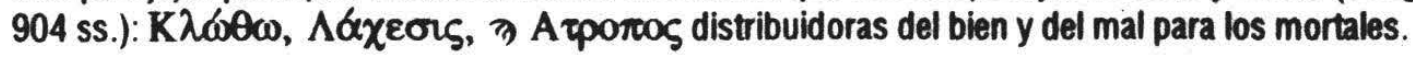




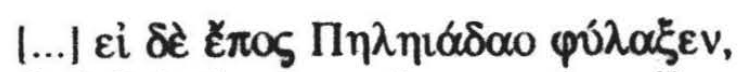

$\hat{\eta} \tau$ ' $\alpha$ 'ं

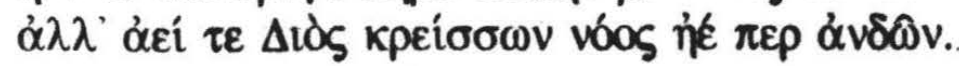

"Si hubiera conservado la palabra del Pelida, hubiera rehuido la negra muerte. Pero siempre el pensamiento de Zeus es más poderoso que el de los hombres..."

llega a las siguientes conclusiones: 1) Deichgräber y Heubeck (Kullmann, 1956, p. 144, n. 2) insisten sobre la üßpis de Patroclo. Kllumann, en el mismo lugar, refuta sosteniendo que no hay transgresión de una mandamiento divino, sino que su ingenuidad (vinklos) y ceguera, le impiden seguir la davertencia de Aquiles y lo empujan a la muerte. El sentido de dichos versos es, para Kullmann, el devenir trágico, y cita a su favor a $\mathrm{H}$. Fränkel a. a. 0.105 s.; 2) Kullmann avanza en su pensamiento sobre la ceguera de Patroclo a la que ve como efecto de la actividad adversa de los dioses: Zeus, que actúa en el oujós del guerrero (691) de modo que éste no puede obedecer las palabras de su rey, y Apolo, que de un modo traidor, lo golpea desde atrás y lo prepara para la muerte a manos de Euforbo y Héctor. Del mismo modo funciona la actividad de Poseidón en la muerte de Alcátco por Idomeneo ( $N, 434 \mathrm{ss}$ ) y aún la enemistad del dios enemigo en $\mathrm{X}, 19 \mathrm{~s}$., donde Aquiles dice que está sin poder frente a Apolo; y 3) Kullmann, asimismo, basándose en el hexámetro 689, concluye que Patroclo tiene liberdad, pero la inteligencia relativamente superior de Zeus hace que se cumpla su $\mu$ î $\alpha$.

Al trabajar con el esquema del "aparato de los dioses" (Götteraparat), Kullmann generaliza las intervenciones divinas "como si el poeta pudiera acudir a ellas a voluntad, a modo de un dispositivo, para hacer avanzar la acción cuando ésta languidece", según Bruno Snell (Snell, 1965, p. 53), con el cual coincidimos. En este sentido, Mueller (Mueller, 1978, pp. 105-123) observa que, si bien es verdad que otros dioses actúan de modo similar, en cada caso estas actividades tienen un significado temático propio. Para nosotros, el proverbial estilo del mito divinohumano, específicamente homérico, pone de relieve el sentido de la existencia terrestre descubierto, insoslayablemente, en el cosmos inteligible de los dioses olimpicos.

Dentro de esta concepción, la muerte de Patroclo se nos presenta no solamente como la excusa para la renuncia de Aquiles a su cólera, sino enraizada y justificada en la actuación del personaje. Su misión junto a Aquiles era advertir

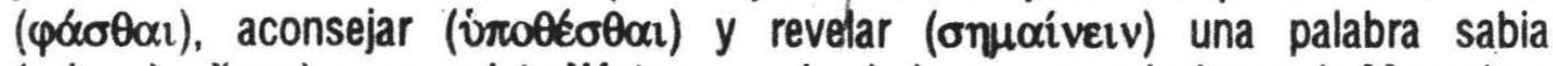

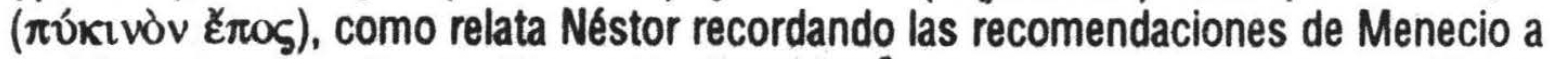
su hijo antes de salir para Troya $(\Lambda, 786-789)^{6}$. Por otra parte, la intervención de Apolo no es artera ni arbitraria, sino que representa el último revés de la propia ceguera.

El "pathos" de la muerte de Patroclo deriva del hecho de que no tiene idea de su inminencia, en contraste con Sarpedón. Transgrede la orden de Aquiles, es cierto, pero el poeta pone el énfasis en su ignorancia y ceguera. el pasaje

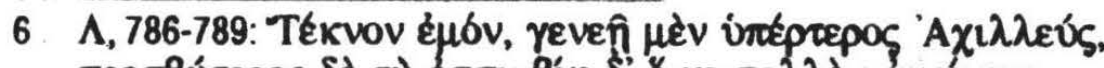

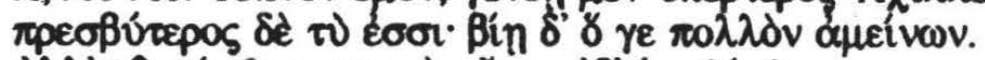

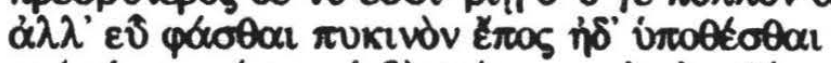

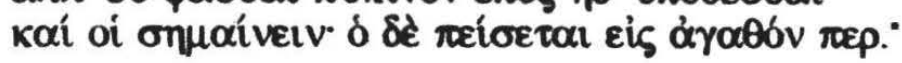


correspondiente (685-805) se abre, precisamente, con estas dos palabras: ¿dóoOn y

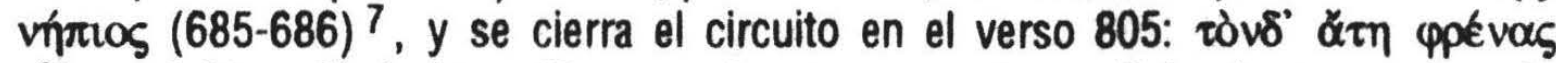

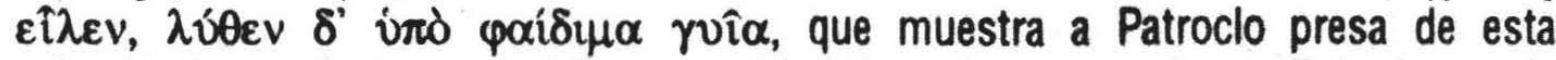
calamidad que afecta su espiritu, sus miembros, y provoca estupor. Esta desgracia le impide comprender que su oponente, por excelencia, es Apolo, 788-789:

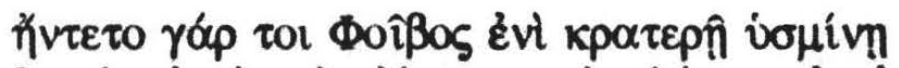

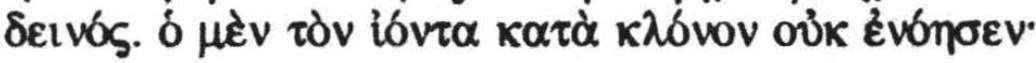

La semántica de ódów y ỡ despliega un contexto opuesto al de Sarpedón. Padecen esta acción en la lliada, entre otros, Agamenón ${ }^{8}$. Este nombre hace ineludible la referencia a su üßpıs, denunciada por Aquiles en A, 203 y Atenea en el mismo Canto, 214, y la palabra no tiene más expresión en el poema. Agamenón, rey de los hombres con rasgos de esta fuerza destructora, como la presenta Hesíodo en Erga, 134 ss. ${ }^{9}$, enfrenta el reino de Zeus al violar la sacralidad del sacerdote de Apolo, Crises, lo que provoca la quiebra entre hombres y deidad. Articulado con él por el padecimiento de su ceguera, Patroclo se inclina hacia el lado de esas fuerzas que causan su propia destrucción y enfrenta también al reino de Zeus en su máximo representante: Apolo. En esto vemos apuntar los rasgos indecisos de una ußppis de Patroclo. No obstante, sostenemos que en el poema es dificil encontrar al hombre "hybrico", excepto Agamenón, tan nitidos se establecen los contornos entre hombres y dioses. Los resguarda especialmente Apolo que, no porque si, preside y cierra la obra ${ }^{10}$.

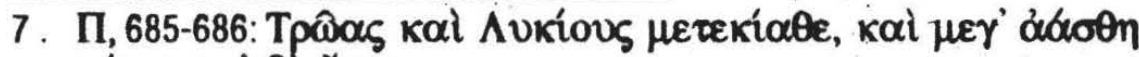

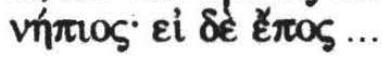

8. En un largo discurso de $\mathrm{T}, 78-144$, Agamenón reconoce y relata el mito de la diosa 7 A enganó al mismo Zeus por lo que éste la arrojó del olimpo al campo dé los mortales. Desde entonces es un flagelo que persigue al hombre y provoca su propria ruina.

9. Según Carlo del Grande (del Grande, 1974, p. 10) "el aporte de la lliada se limita a esto: Üßpis es la arrogancia de un hombre contra un semejante suyo de la misma clase social." Sin embargo, otro costado muestra Hesíodo en el mito de las eades, donde la hace aparecer con fuerza destructora, signo de ninguna sensatez y de impiedad, en los hombres de plata: Erga, 134-135:

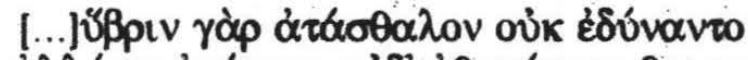

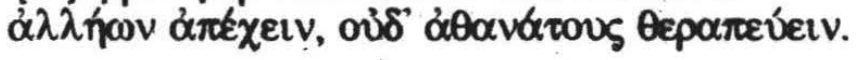

"No podian alejar de ellos la soberbia desmesura que los arrojaba unos contra otros."

El hombre de esa edad está caracterizado como $\mu \varepsilon \gamma \alpha$ vímios (131), es decir, el muy ingenuo o que

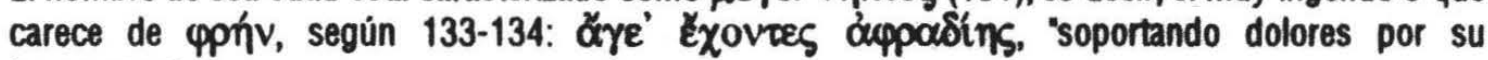
insensatez:"

10. En Istmica IV, 14 y 16, Pindaro advierte lo que un héroe homérico ya sabe y si no, lo aprende, entre

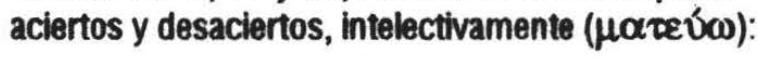

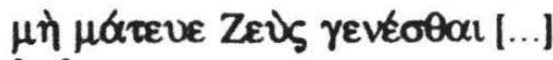

$[\ldots]$

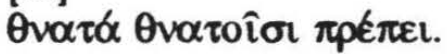

"No busques llegar a ser Zeus [. . ] A los mortales les corresponden las cosas mortales: 


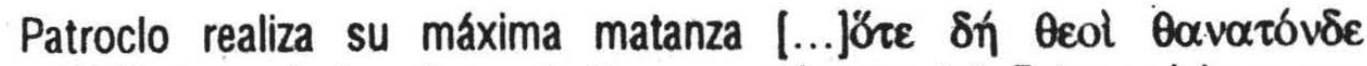
$\kappa \alpha ́ \lambda \varepsilon \sigma \sigma \alpha \nu$ (693), "cuando los dioses te llamaron a la muerte". Estas palabras que en X 297 expresan el reconocimiento final del héros, en boca de Héctor, están ausentes en Patroclo de quien sólo las pronuncia el poeta. Contienen el significado de que tanto la vida como la muerte vienen de los dioses inmortales. Este es el modo acostumbrado y el descubrimiento de la disparidad mortal en el mito divinohumano. Es frecuente en la secuencia de los hexámetros escuchar la exhortación a la acción para ver si un dios quiere otorgarnos la victoria a nosotros 0 a los enemigos. La confrontación asi planteada está dispuesta, más allá de los destinos individuales, en dos términos, muerte y vida, entre dos instancias divinas, $\mu$ ôि $\alpha$ y dioses, cuya relación oscila entre enfrentamiento e ineludible concordia, articuladas a través del dolor de la divinidad (caso modelo: Sarpedón, $\Pi$ 431-361). Esta relación regula todo el hacer heroico del hombre.

En los versos 698-711 11 , que preludian la muerte de Patroclo, Apolo assume nítidamente la oposición que marcábamos siendo al mismo tiempo muerte (para patroclo) y vida (para los troyanos). Patroclo, deslumbrado, víctima de su propia ceguera, no acierta con la intelección de su muerte y su sentido. Sólo atina a apartarse por temor a la cólera del dios (711). En este punto convergen sobre el guerrero las dos $\mu$ ńveıs: la destructora y perdurante de su rey $(A, 2$, ov̉io $\mu \varepsilon v \eta)$, bajo cuyos efectos lo envia a la batalla y le otorga sus armas ( $\Pi, 61$ ss.), y la $\mu$ îvis de Apolo que se desencadena y actúa a partir del momento en que Patroclo pretende tomar la ciudadela por encima de lo dispuesto ( $\alpha \hat{\imath} \sigma \alpha$ 705). La de Apolo es englobante, afecta a todo ese universo con sus elementos, naturaleza y hombres, y resguardada en la instancia última de la $\mu$ ô̂pa. La de Aquiles, originada en la querella de los jefes griegos, en el ágora, irrumpe en la batalla cuyas consecuencias desgraciadas se acumulan en los enfrentamientos hasta la caída de Patroclo, verdadera crisis en la vida de Aquiles.

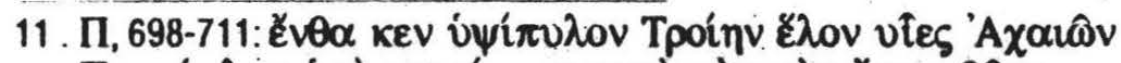

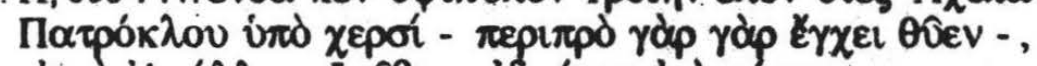

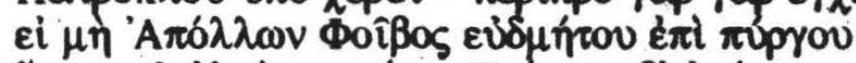

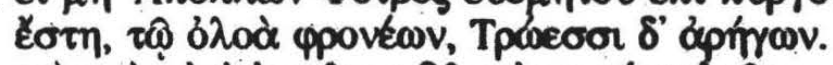

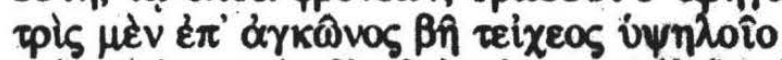

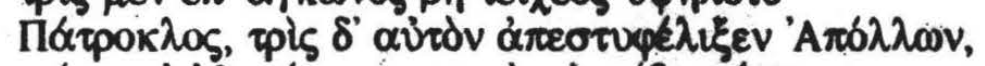

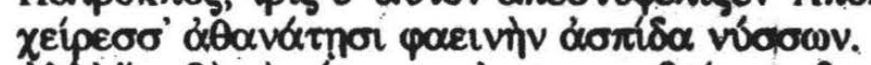

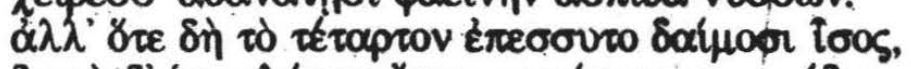

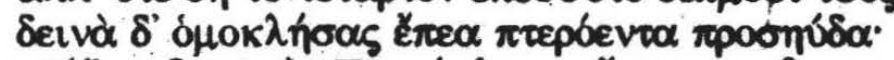

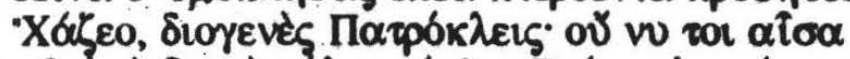

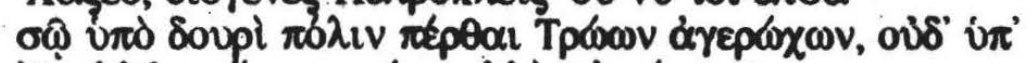

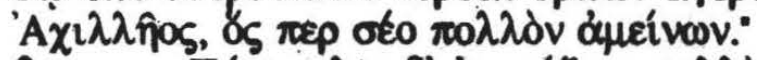

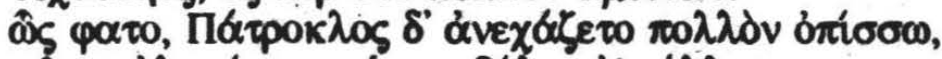

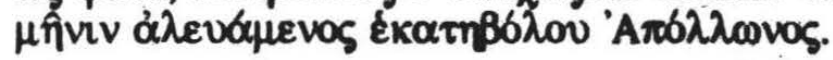

"All los hijos de los aqueos hubieran tomado Troya por medio de las manos de Patroclo - pues mataba sobresaliendo con su lanza - si Febo Apolo no se hublera plantado sobre el muro bien construido, meditando, terrible, la ruina para este, pero socorriendo a los troyanos. Tres veces se dirigió Patroclo hacta un ángulo del elevado muro y tres veces lo espantó Apolo agitando con sus manos inmortales el esplendente escudo. Pero cuando, por cuarta vez, se lanzaba, semejante a un dios, terriblemente le gritó aladas palabras: "Apártate, divino Patroclo. Por cierto, no está destinado para ti destruir la ciudad de los troyanos valientes, ni tampoco para Aquiles, el cual es mucho mejor que tú." Asi dijo, y Patrocio se apartaba, esquivando la cólera de Apolo, el que hiere de lejos." 
Una serie de comparaciones enmarca la muerte de Patroclo, como también lo están, por ejemplo, la de Sarpedón y Héctor. Son verdaderos centros líricos en el poema que, en el caso que nos ocupa, exploran las energlas de muerte, ferocidad y violencia que surgen de la conmoción del oupós del hombre. Preside le serie la comparación de Patroclo con un león (752-754) ${ }^{12}$, en el momento en que mata a Cebrión, cochero de Héctor. Hay una nota que preludia la propia destrucción incomprensible: la violencia irrefrenable del león-Patroclo contrasta con la imagen circunscripta de los establos-ciudad propuesta como objetivo de su asalto, sin embargo, termina siendo víctima de su propia fuerza. A continuación (756-759) ${ }^{13}$, la ferocidad del animal encuentra otra semejante que se opone con la misma soberbia. Héctor-león y Patroclo-león se desgarran en la cima de un monte en torno a una cierva muerta (cadáver de Cebrión). Y, en tercer lugar, la ferocidad se translada a los elementos en la contienda de los vientos enemigos, Euro y Noto, que produce la destrucción de la naturaleza vegetal, como apogeo de la matanza que anula toda compresión. (765-771) ${ }^{14}$.

A través de estas tres escalas llegamos al despliegue final de la batalla incomprensible, pero equilibrada. Mas, cuando este equilibrio se rompe a favor de los aqueos, las cosas han salido de su cauce, vimèp $\alpha \hat{i} \sigma \alpha v$ (780), por encima de lo dispuesto. Es el momento en que, por segunda vez, Apolo enfrenta a Patroclo, pero achora con el atributo $\delta \varepsilon ı$ wós (789), que, como en A, lo manifiesta en toda su terribilidad. Pero Patroclo no lo vio (ov̉e évóną).

Estamos frente a un encuentro o combate no convencional: es un enfrentamiento sin armas, como es el enfrentamiento del conocimiento heroico. Frente al terrible dios el intelecto humano (vóos) se escurecio (805). Apolo lo

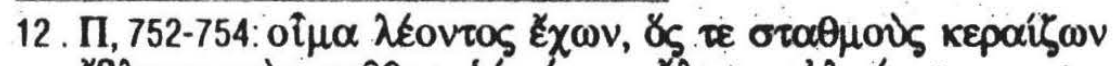

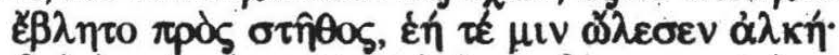

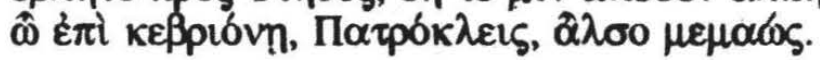

"Con el impetu de un león que, al devastar los establos es herido en el pecho y su propia fuerza lo mata, así te arrojaste, Patroclo, enardecido, sobre Cebrión."

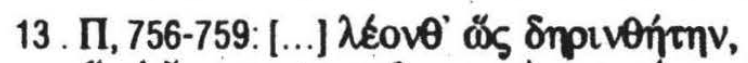

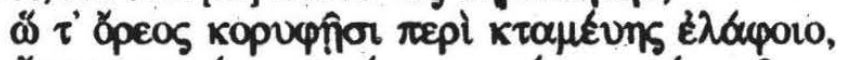

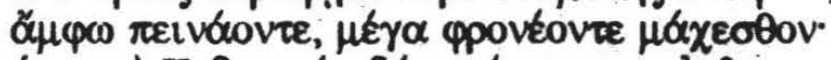

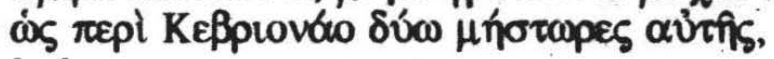

$[\ldots]$

-... se desgarraban como leones que en la cima de un monte luchan en torno a una cierva muerta, ambos forcejeaban y se acometan con el fin de matarse. Asl los dos jefes se lanzaban uno contra el otro, con gran gritería, en torno a Cebrión..."

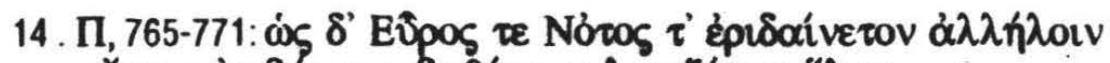

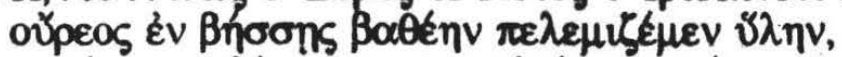

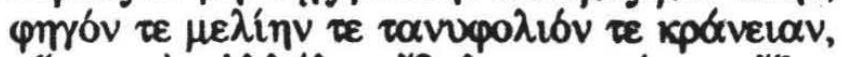

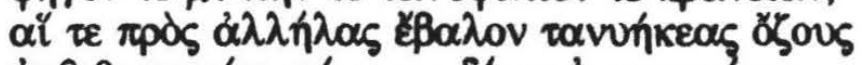

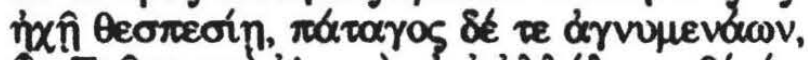

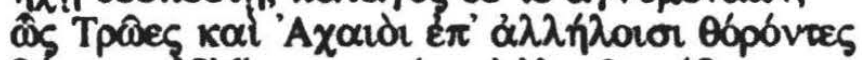

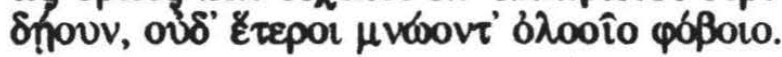

"Como el Euro y el Noto contienden en la espesura de un monte, agitando la densa vegetación, el fresno, la encina y el duro cornejo, y éstos arrojan, unos contra otros, sus ramas puntiagudas, con inmenso estrépido y crujido de las que se rompen, asi los troyanos y los aqueos se mataban y no se acordaban de la huida." 
desviste despaciosamente, pero Patroclo queda incomprensible ante si mismo. Un guerrero opaco lo hiere desde atrás, Euforbo, y el golpe de gracia se lo da Héctor.

En la intervención divina de Apolo vemos, en primer lugar, a un dios que regula el destino de Patroclo, no lo provoca, sino que lo secunda. Patroclo iba a morir en un rol extraño a su naturaleza, con las armas ajenas, que, digamos de paso, junto con el guerrero forman una unidad heroica.

En segundo lugar, es el que trae la muerte en la lliada, (éкńßoдos). Es el primer dios que aparece y lo hace al ser invocado por Crises. Su aparición está acompañada de terror y misterio y es necesario una nueva plegaria para aplacarlo. La mortalidad, connatural al hombre, es el tema que lo imputsa contra Aquiles, cuando se revela a sí mismo después de haberlo alejado de las puertas de Troya, $\mathbf{X}$, 7-13:

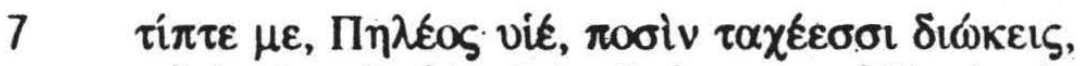

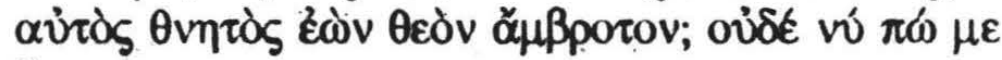
Eे $\gamma$ wos

En tercer lugar, Apolo es el dios que más insiste en la distinción entre hombres y dioses, por ejemplo, en $\Phi 462$ ss:

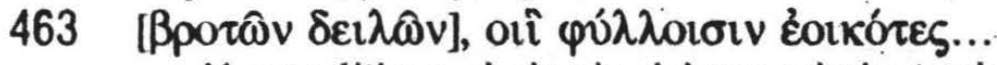

Y, por último, derivado del conocimiento de la mortalidad, está el sentido de la medida o moderación, con el cual Apolo también está asociado. En su primera intervención llega para vengar el ultraje de Agamenón a Crises, insulto que representa una violación del $\alpha i \delta \omega s$. En el último canto, en la asamblea divina, acusa a Aquiles de faltar a la piedad y violar el aỉóç en su tratamiento del cadáver de Héctor $(\Omega, 41-54)$. Este discurso, en la apertura del canto, gula directamente a la conversión de Aquiles. En este punto, dice Mueller (op.cit.), el que trae la muerte en la lliada, podemos decir que es, no menos que el dios de Delfos, también el dios del "conócete a ti mismo".

En el episodio de la muerte de Patroclo confluyen estos modos divinos en los signos claros de sus advertencias: escudo, que encandila; voz terrible y alada que se dirige al vóos; mano que desnuda y verifica la terribilidad. Pero Patroclo muere sin comprender. Por el contrario, esta muerte se proyecta en el conocimiento de Aquiles que, a partir de aqul adquiere su experiencia dolorosa y vicaria.

La comparación que cierra la calda $(\Pi, 823-828)^{15}$, en forma muy elocuente, despliega el enfrentamiento entre dos fuerzas bestiales de distinta intensidad: Héctor-león y Patroclo-jaball, Aunque el jaball es siempre víctima del

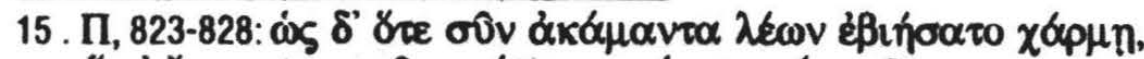

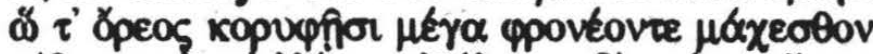

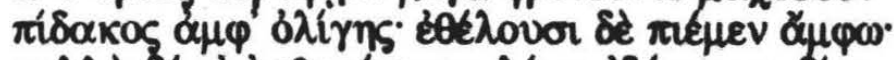

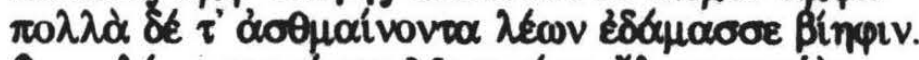

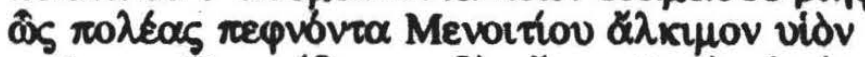

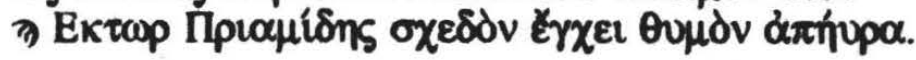

"Como cuando el león ataca con brío al infatigable jaball, los cuales luchan con el fin de matarse en la cima de un monte, por una pequeña fuente de agua; y quieren beber ambos, pero el león mata con su fuerza al interminablemente jadeante jaball, asi Héctor Priamida arrebató con su espada la vida al esforzado hijo de Menencio que a tantos habla matado." 
felino, no obstante no se conmuove, ataca hasta las últimas consecuencias, prefiere el azar del encuentro que es siempre para él su muerte segura. El premio es una pequeña fuente de agua cuya contrastante pequeñez y la anhelada calma desata la codida de las fuerzas empeñadas, hasta la muerte, por la vida.

De ningún modo pretendemos una valoración de culpa y consecuente castigo en la muerte de Patroclo. La suya era inevitable, como se puede demostrar. Hemos intentado distinguir que, en contraste con la de Sarpedón, muere sin reconocer su verdadero rol y mortalidad, victima de la divinidad que más acentúa la diferenciación entre hombres y dioses, a la que no comprende, y de un mortal.

Antes de morir, atisba un reconocimiento, pero aún ingenuo. Piensa que lo vencieron porque le quitaron la armadura, pero guarda aún soberbia confianza en sus fuerzas, $844-850^{16}$ :

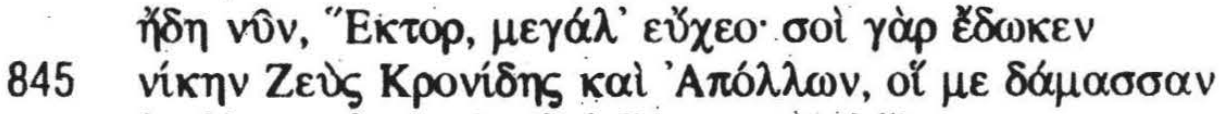

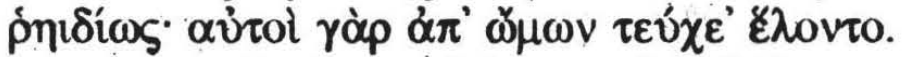

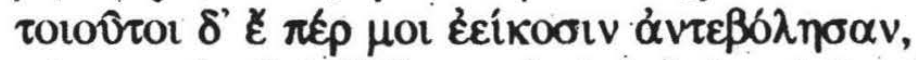

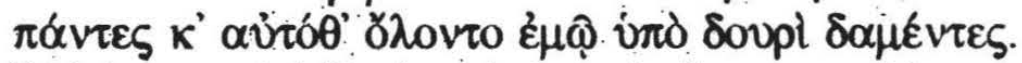

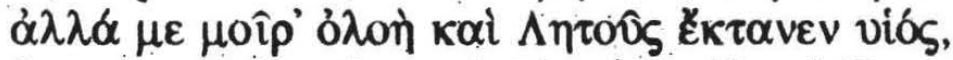

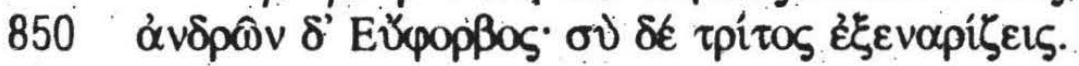

En estas palabras pone en evidencia que su destino mortal le ha llegado en forma inesperada, por la coyuntura del enfrentamiento de los dioses contra él. La posibilidad frustrada en el pasado (846-847), como si hubiera podido ser de otra manera, confirma nuestra presunción de la irrealidad de su móvil, es decir, la acción sin intelección previa.

Bibliografia

Los textos griegos han sido tomados de la edición de AMEIZ-HENTZE: Homer llias, Leipizig und Berlin, Teubner, 1927.

ChantRaine, P. Dictionnaire etymologique de la langue grecque. Paris: Klincksieck, 1984.

DEL GRANDE, C. Hybris. Napoli: Ricciardi, 1947.

DE ROMILlY, J. Perspectives actuelles sur l'épopée homérique. Paris: Presses Universitaires de France, 1983.

16. П, 844-850: "Ciertamente, Héctor, ufánate mucho, ahora. Pues Zeus Cronida y Apolo te dieron la victoria, los que a mi me mataron. Es decir, ellos arrancaron las armas de mis hombros. Pero, si me hubieran enfrentando veinte como tú, todos hubieran muerto vencidos por mi lanza. Por el contrario, la $\mu$ ô $\rho \alpha$ destructora y el hijo de Leto me mataron, y Euforbo, de entre los hombres. Y tú me matas en tercer lugar." 
GRIFFIN, M. Life and death in Homer. Oxford, 1980.

KULLMaNN, W. Das Wirken der Götter in der Ilias. Berlin: Akademie Verlag, 1956.

MAZON, P. Introduction a I'lliade. Paris: Belles Lettres, 1959.

MUELLER, M. Knowledge and Delusion in the lliad. En: Whight, J. Essays on the Iliad. Bloomington \& London: Indiana U. Press, 1978. pp. 105-123.

SCHELIHA, R. Patroklos - Gedanken über Homers Dichtung und Gestalten. Basel: Benno Schwabe, 1943.

SNELL, B. Las fuentes del pensamiento europeo. Traducción de José Vives. Madrid: Razon y Fe, 1965.

WHITMAN, C. Achilles: evolution of a hero. En: Homer and the heroic tradition. Cambridge-Massachustts: Harvard U. Press, 1963. pp. 181-220.

WILLCOCK, M. M. Some Aspects of the Gods in the Iliad. En: Wright, J. Essays on the Iliad. Bloomington \& London: Indiana U. Press, 1978. pp. 58-69. 